\title{
A percepção do Idoso sobre a Saúde e Qualidade de Vida na Terceira Idade
}

Irineide Beserra Braga ${ }^{1}$; Elinez Beserra Braga ${ }^{2}$; Maria Cristina de Araújo Oliveira ${ }^{3}$; José Demontier Guedes ${ }^{4}$

Resumo: O presente estudo visa discutir a qualidade de vida no envelhecimento, tecendo comentários sobre a prevenção de doenças, promoção da saúde, bem como aspectos relacionados ao convívio e relacionamento familiar. O envelhecimento tende a ser uma fase esperada na vida das pessoas. Não se trata de uma mera passagem de tempo. Embora tenha havido melhorias quanto aos problemas ligados à saúde, constata-se que, em se tratando da assistência aos idosos, estas ainda parecem precárias, pois são limitados os programas ofertados na rede de atenção à saúde pública. O objetivo foi conhecer a percepção dos idosos atendidos no PSF da comunidade de Redonda, no município de Icapuí - CE, sobre qualidade de vida e o que eles necessitam para poder envelhecer de uma forma saudável. A realização deste estudo possibilitou um melhor conhecimento da percepção do idoso sobre a qualidade de vida na terceira idade, bem como a compreensão de suas relações no convívio familiar e comunitário.

Palavras-chave: Envelhecimento; Saúde; Terceira Idade.

\section{The Perception of the Elderly on Health and Quality of Life in Third Age}

\begin{abstract}
This study aims to discuss the quality of life in aging, commenting on disease prevention, health promotion, and issues related to living and family relationships. Aging tends to be an expected phase in people's lives. It is not a mere passage of time. Although there have been improvements on the problems related to health, it appears that, when it comes to care for the elderly, they still seem precarious, as the programs offered in the network of attention to public health are limited. The objective was to know the perception of the elderly seen in the FHP of Redonda community in the municipality of Icapuí - CE on quality of life and what they need to be able to age in a healthy way. This study enabled a better understanding of the perception of the elderly on the quality of life in old age, as well as understanding their relations in family and community life.
\end{abstract}

Keywords: Aging; health; Third Age.

\section{Introdução}

É notório o quanto o envelhecimento populacional vem crescendo graças à longevidade proporcionada pelos avanços da Medicina que reduziu as taxas de mortalidade e fecundidade. Essa mudança social e demográfica trouxe consigo outras implicações e conceitos sobre envelhecimento como afirma Celich (2008, p. 14):

\footnotetext{
${ }^{1}$ Psicóloga pela Faculdade Leão Sampaio - FALS. Mestre em Ciências da Educação, Especialista em Saúde Mental pela Faculdade Leão Sampaio - FALS. Email: irineidebraga@msn.com.

${ }^{2}$ Enfermeira. E-mail: elinezbraga@ hotmail.com;

${ }^{3}$ Pedagoga. Pós graduada em Literatura e redação, Gestão Escolar e Psicopedagogia Clínica e Institucional. Email: Cris.eudes @ hotmail.com; ${ }^{4}$ Pedagogo. Especialista em Língua portuguesa e arte-educação. Mestrando em Ciências da educação. E-mail: proerddemontierguedes@ig.com.br.
} 


\begin{abstract}
Envelhecer não deve significar, necessariamente, um declínio ou perda das funções cognitivas e corporais. Apesar de se constituir em um processo natural, o envelhecimento não ocorre de forma homogênea. Cada idoso é um ser único que, ao longo da sua trajetória de vida, foi influenciado por eventos de natureza fisiológica, patológica, psicológica, social, cultural, ambiental e econômica, os quais influenciam na qualidade de vida da velhice.
\end{abstract}

Sendo assim, o envelhecimento é uma fase esperada na vida de todas as pessoas. Não é uma mera passagem de tempo. É a manifestação de eventos biológicos que ocorrem ao longo de um período (COSTA; MATIAS, 2005). Em todos os países, o processo do envelhecimento pode variar, apresentando características diferentes de acordo com as suas condições de vida (DAWALIBI et al, 2013). Mas é preciso ressaltar que a forma como se envelhece depende dos comportamentos nas fases anteriores, de um planejamento para idade avançada e do significado que envelhecer tem para cada indivíduo.

Ainda que a realidade tenha se modificado consideravelmente no que diz respeito ao processo de envelhecimento, é importante recordar que, quanto mais velha a pessoa vai ficando, inevitavelmente, sua qualidade de vida no que tange aos sistemas corporais vai piorando. O sistema imunológico, por exemplo, fica mais suscetível a infecções; o nervoso sofre alterações significativas no funcionamento, o sistema cardiorrespiratório fica menos resistente, entre outras mudanças. (LINDEN JÚNIOR; TRINDADE, 2013).

No entanto, não se pode pensar que a qualidade de vida da pessoa idosa relaciona-se apenas a aspectos biológicos; pelo contrário se encontra intimamente relacionada às dimensões psicológica, econômica, cultural e social, os quais contribuem não somente para a sua autonomia funcional, para a sua interação social bem como também para a diminuição da morbimortalidade. (VAGETTI et al, 2013).

Embora haja uma melhoria com relação aos problemas ligados à saúde, constata-se que em se tratando da assistência aos idosos ainda é precária e limitada à participação ou à aceitação destes nos programas ofertados na rede de atenção à saúde. A população idosa necessita, portanto, de uma atenção voltada para a sua realidade, capaz de proporcionar-lhes qualidade de vida, com um envelhecimento saudável. De maneira que o idoso permaneça junto de seus familiares e amigos o maior tempo possível, com autonomia e bem-estar.

Concordando com Celich (2008), identifica-se que o envelhecimento não significa necessariamente sinônimo de doença. Alguns idosos conseguem manter sua saúde. Para que isso aconteça, é necessário praticar atividades físicas, interagir em grupos, ter atividades de lazer, de forma a alcançar um bom estado físico e psicológico.

Assim, pesquisas que possam primar pelo reconhecimento das necessidades que os idosos identificam no contexto do atendimento em saúde, das ações preventivas e de promoção da qualidade 
de vida, dos grupos de convivência e troca de experiências entre os idosos são de fundamental importância, pois se configuram como uma ferramenta que fundamentará as ações futuras que potencializem o trabalho de melhoria da qualidade de vida da população idosa.

A relevância deste estudo está, sobremaneira, na busca pelo conhecimento e percepção dos idosos atendidos no PSF da comunidade de Redonda, no município de Icapuí - CE, sobre o que é qualidade de vida e o que eles necessitam para poder envelhecer de uma forma saudável.

Dessa forma, a pesquisa implicará numa produção acerca dos processos de saúde dos idosos, servindo de base para trabalhos posteriores que possam contribuir para melhoria da qualidade de vida dos participantes, atuando num nível de educação e prevenção de doenças características do processo de envelhecimento.

O objetivo deste trabalho é, portanto, investigar a percepção do idoso sobre a saúde e a qualidade de vida no seu contexto comunitário. E como objetivos específicos elencados nesta pesquisa: verificar os hábitos dos idosos em relação à saúde e qualidade de vida; identificar se há ações de cunho preventivo para doenças geriátricas e ainda observar as práticas existentes na comunidade que promovem a saúde e qualidade de vida na terceira idade.

\section{Método}

A presente pesquisa apresenta abordagem qualitativa, porque se propõe a trabalhar com as concepções e as opiniões dos sujeitos, valorizando, pois, a sua subjetividade (MINAYO, 2007), tendo como base um estudo exploratório-descritivo, já que focaliza os aspectos inerentes à qualidade de vida do idoso, tentando conhecê-los.

Foi selecionado como local para a realização deste estudo, a comunidade de Picos/ Icapuí Ceará, especificamente os moradores idosos residentes nesta localidade. A população ou o universo desta pesquisa, segundo Marconi e Lakatos (1996), é o conjunto de indivíduos que partilham de, pelo menos, uma característica em comum. Sendo assim, contamos com uma população de vinte e dois idosos. A amostra aqui descrita pode ser denominada, segundo Gil (2002), como amostragem aleatória simples, já que fora utilizada devido à facilidade da aplicação da mesma, uma vez que não requer conhecimento prévio da população pesquisada. Desse modo, foram convidados a participar desta pesquisa seis idosos que residem na comunidade de Picos.

A coleta de dados aconteceu mediante a realização de uma entrevista semiestruturada, a qual consistiu num diálogo acerca da temática estudada a partir de um roteiro orientador de questionamentos formulados previamente. No entanto, à medida que a entrevista foi acontecendo outras perguntas foram feitas, quando o entrevistador considerou necessário. (MINAYO, 2007). 
As entrevistas foram gravadas em aparelho de áudio e depois transcritas conforme foram faladas, a fim de garantir a fidedignidade dos dados obtidos. Ao realizar cada entrevista, foi explicado para o idoso o objetivo do estudo, frisado que poderia desistir no momento que desejasse, além de ser lido o Termo de Consentimento Livre e Esclarecido - TCLE e solicitado a sua assinatura.

Para proteger as identidades dos colaboradores deste estudo foram atribuídos pseudônimos, especificamente nomes de idosos retratados em desenhos animados e séries de televisão: Dona Clotilde, Dona Neves, Senhor Jaiminho, Tio Barnabé, Senhor Fredricksen e Dona Benta.

Para a análise dos dados, foi estabelecido um diálogo entre as opiniões dos participantes desta pesquisa e dos teóricos que abordam o tema aqui estudado, sendo os resultados obtidos organizados em três categorias assim descritas: Envelhecimento e qualidade de vida: algumas concepções; Melhorando a qualidade de vida: prevenção de doenças e promoção de saúde; Relacionamento familiar e convívio comunitário.

\section{Resultados e Discussão}

Participaram desta pesquisa seis idosos, sendo 3 de cada sexo, com idade entre 62 e 90 anos, aposentados recebendo em média 2 salários mínimos.

Quadro 1: Caracterização socioeconômica dos participantes da pesquisa

\begin{tabular}{|l|l|l|l|l|}
\hline Pseudônimo & \multicolumn{1}{|c|}{ Sexo } & \multicolumn{1}{|c|}{ Idade } & \multicolumn{1}{|c|}{ Renda familiar } & \multicolumn{1}{c|}{ Escolaridade } \\
\hline Dona Benta & Feminino & 69 anos & 1 salário mínimo & Não alfabetizado \\
\hline Dona Neves & Feminino & 63 anos & 2 salários mínimos & Alfabetizado \\
\hline Dona Clotilde & Feminino & 62 anos & 2 salários mínimos & Alfabetizado \\
\hline Tio Barnabé & Masculino & 70 anos & 2 salários mínimos & Alfabetizado \\
\hline $\begin{array}{l}\text { Senhor } \\
\text { Jaiminho }\end{array}$ & Masculino & 90 anos & 3 salários mínimos & Não alfabetizado. \\
\hline $\begin{array}{l}\text { Senhor } \\
\text { Fredricksen }\end{array}$ & Masculino & 62 anos & 2 salários mínimos & Não alfabetizado. \\
\hline
\end{tabular}

Fonte: Dados da Pesquisa - Picos, Icapuí, Ceará, 2014.

\section{Envelhecimento e qualidade de vida: algumas concepções}

Costa e Matias (2005) e Sakumoto et al (2010) afirmam que o envelhecimento é uma etapa vivenciada por todos os seres humanos, a qual é construída ao longo do tempo, manifestando-se a partir de modificações biológicas, sociais e culturais, as quais vêm acompanhadas de aprendizados e 
amadurecimento perante as situações da vida. O pensamento dos autores referidos logo acima vão ao encontro do que foi dito por alguns participantes desta pesquisa: "O envelhecimento é com a continuação do tempo, você vai vivendo e envelhecendo..." (DONA NEVES). "Envelhecer significa não só aparência, mas sim com as experiências que a gente passa com o passar dos anos" (TIO BARNABÉ).

Dona Clotilde e Senhor Jaiminho aproximam-se dessas opiniões ao pensar o envelhecimento como uma fase que acontece com o passar do tempo. No entanto, vão além, pois expressam uma visão negativa, triste, pessimista sobre essa etapa da vida. "O envelhecimento significa o passar do tempo, uma idade avançada... É triste o envelhecimento... É uma praga!” (DONA CLOTILDE).

Minha filha é uma palavra que num posso compreender... Não posso nem lhe entender... Para mim, envelhecer é a pessoa que luta muito, e se preocupa muito, eu creio que seja assim... A pessoa se preocupa muito na luta, às vezes e tem umas coisas pra fazer e acaba se preocupando... Os anos vão passando e vai ficando velho. Vai ficando pior. A pessoa quanto mais luta, mais velho vai ficando, não é, minha filha? (SENHOR JAIMINHO).

Mayrink e Cunha (2011) suscitam reflexão sobre essa questão, ao afirmarem que, por mais avanços, progressos que se tenha tido no campo da saúde, é inevitável lembrar que, quanto mais velho o corpo vai ficando, a pessoa tende a apresentar algumas limitações, quer seja físicas, quer seja de decisões, até mesmo como resultado das outras fases da sua vida. Essa realidade pode torná-la dependente dos outros ou até mesmo isolá-la socialmente, o que consequentemente a leva a ter uma visão negativa do processo de envelhecimento.

A fala de Dona Benta chama atenção, porque além de compreender a velhice como um processo que traz consequências negativas, frisa a necessidade de "lutar" contra isso:

Os anos vão se passando e a gente vai ficando velha, vai caindo na idade. A gente num vai se preocupar porque cada um tem nossa passagem na velhice, mas a gente num vai deixar a velhice tomar conta da gente não... A gente tem que renovar, o que é renovar a velhice? Passear, gozar sua velhice, se cuidar, se zelar, ter uma velhice de meninice, se a gente for entristecer, a gente se acaba muito mais. Você envelhece muito mais. (DONA BENTA).

A compreensão de "lutar" contra a velhice é interessante para ser analisada, já que significa que ela procura não se abater com os limites impostos pelo envelhecimento, procurando vivenciar de forma alegre essa etapa da vida, com o que ela tem a oferecer.

Sob essa perspectiva, é importante analisar as relações existentes entre qualidade de vida e terceira idade. Quando os entrevistados foram questionados sobre o significado da qualidade de vida, eles responderam: "Qualidade de vida é ter saúde, trabalhar e viver bem... É viver tendo o que comer... É uma vida boa de viver saudável... A qualidade que acho boa é essa dai..." (DONA CLOTILDE). 
Para Dona Neves, "Qualidade de vida é uma boa vida, saúde e uma boa estrutura, isso pra mim é uma qualidade de vida".

Qualidade de vida, eu entendo é que você tiver um salário mais digno, um salário melhor, que você vive despreocupada. Você não tem problemas de saúde, você num deve a ninguém, não tem problemas de dever. Ter uma boa família, um bom filho, umas boas filhas... (DONA BENTA).

Celich (2008) afirma que a velhice pode, sim, ser marcada por uma boa qualidade de vida. O envelhecimento não implica em doença, sofrimento, tristeza, isolamento. Muitos idosos conseguem envelhecer de forma saudável, desde que consigam ter acesso ao serviço de saúde, realizar suas atividades cotidianas, interagir com grupos e com os familiares, além de, quando não há restrições médicas, realizar exercício físico.

Para Dawalibi et al (2013), por sua vez, a qualidade de vida na terceira idade encontra-se intimamente relacionada com a autoestima e o bem-estar pessoal do idoso, o que abrange um conjunto de aspectos: capacidade funcional, nível socioeconômico, estado emocional, interação social, atividade intelectual, autocuidado, suporte familiar, estado de saúde, valores culturais, religiosidade, estilo de vida, satisfação com o emprego e/ ou com as atividades da vida diária e com ambiente em que vive. Concepção que pode ser identificada nas opiniões a seguir: "É você ter uma vida boa, não matar sua cabeça com nada... Ter sua boa morada, ter saúde, seu bom transporte e não faltar a coisa que você deseja e poder comprar o que quiser. Isso é uma qualidade de vida boa que você tem..." (SENHOR FREDRICKSEN). Ou ainda, conforme Tio Barnabé: "Qualidade de vida é poder disfrutar de uma boa vida, tendo saúde, uma vida sadia, uma alimentação boa, uma família estruturada".

A qualidade de vida é a pessoa que não tem muita preocupação. Qualidade de vida é aquela pessoa que tudo que faz é com aquela alegria, com aquele amor, sem preocupação com nada. Qualidade de vida é aquela pessoa que não tem preocupação de nada, num liga para o passado. (SENHOR JAIMINHO).

\section{Melhorando a qualidade de vida: prevenção de doenças e promoção da saúde}

A capacidade funcional, apontada por Veras (2009), para realização de pequenas ou grandes atividades confere aos idosos um sentimento de autonomia para que se sintam bem nesta fase da vida. Logo, qualidade de vida tem uma relação direta com o modo de viver de cada sujeito. Nesse sentido, ver-se claramente que os contextos interferem nas vidas dos idosos quando eles expõem o que acreditam que seja qualidade de vida: 
É você ter uma vida boa, não matar sua cabeça com nada... Ter sua boa morada, ter saúde, seu bom transporte e não falta a coisa que você deseja e poder comprar. Isso é uma qualidade de vida boa que você tem... "Rapaz, fulano de tal tem uma vida boa... Não faz mal a ninguém, ele tem uma vida boa, é saudoso, é tranquilo...” Essa pessoa tem uma vida boa, todo mundo gosta dela... (SENHOR FREDRICKSEN).

Ou aquilo que consideram não ser qualidade de vida, ou mesmo ser ruim, como diz Dona Benta:

É não ter o que comer, é não ter saúde, graças a Deus eu pra idade que tenho, eu acho que tenho uma saúde de criança, pelo que eu faço o que eu fiz na minha infância eu cheguei até o dia de hoje... Eu tenho uma qualidade muito boa, com espírito de jovem, pra idade que tenho hoje.

É preciso considerar, como diz Celich (2008), que existe a necessidade de se pensar modos de proporcionar qualidade de vida, mesmo diante das mudanças pelas quais os idosos enfrentam nos contextos em que vivem.

Nesse sentido, Dawalibi et al (2013) fala sobre a importância da atividade física para a terceira idade, em que o individuo possa optar por um estilo de vida mais adequado, o qual inclui mudanças de hábitos alimentares e atividade física regular. Como os entrevistados comentaram: "Faço, pra minha saúde. Se eu num fizer uma atividade física é pior pra velhice. Se agente deixar a velhice tomar conta e achar que esta velha não pode se cuidar, eu acho que fica pior pra velhice. Então agente deve se cuidar mais na velhice do que na infância”. (DONA BENTA).

Faço sim, minha caminhada. Eu faço atrás das minhas melhorias de vida né, minha filha? Ás vezes os médicos manda a gente caminhar né, minha filha? Para devolver o corpo da gente ali... Como filha conhece a historia, nosso organismo dentro é como uma maquina... Você conhece a historia, minha filha? Aquilo é como uma maquina de navio, de um barco, tem que ter um óleo, enquanto agente caminha, mais amacia aqueles ossos e os membros vivem controlados, eu creio que seja assim né? (SENHOR JAIMINHO).

Outros entrevistados afirmam que não fazem nenhum exercício físico. "Não realizo atividade física, porque não gosto de fazer" (DONA NEVES). A opinião de Tio Barnabé chama atenção, porque justifica a não realização de atividade física pelo fato de ter uma rotina árdua de trabalho. "Faço não porque já trabalho muito! Vou pro meu roçado, às vezes vou pro mar pegar um peixe... Minha filha, eu num paro não! Também graças a Deus num tenho problema de saúde...”.

Segundo Chacra (2002) apud Baricelli et al (2012), quando as pessoas realizam uma atividade em grupo e interagem e se identificam umas com as outras, essa ação constitui-se como um estímulo aos relacionamentos interpessoais, melhorando sua autoestima, sua qualidade de vida, fomentando sua autonomia e promovendo sua inserção na sociedade. Ainda nessa perspectiva, conforme Alvarenga et al (2009), para envelhecer de forma bem sucedida é preciso que, além do 
estímulo ao funcionamento físico e mental, as atividades sociais estejam presentes. As falas abaixo demonstram isso: "É eu participo do posto de saúde, assim no grupo, no grupo de... Dos idosos, sendo acompanhado pelos médicos... Assim, me sinto bem... Me faz bem conviver com os outros..." (DONA CLOTILDE). Já para Tio Barnabé: "Eu frequento os cultos 2 vezes por semana. Quando tem reunião da associação eu vou. No posto, vou poucas vezes até porque não sinto nada". Na visão do Senhor Jaiminho: “Às vezes na igreja, eu participo. Não deixo de participar não. No posto de saúde vou também, não vou voluntariamente, se me convidarem eu posso chegar até lá...”

$\mathrm{Na}$ assembleia de Deus, eu participo na igreja porque apesar de tudo, não há outro caminho a não ser servir a Deus. Graças a Deus pela oportunidade que deram essa confiança, esse respeito que o povo tem a mim. Graças a Deus eu sou encarregado no trabalho de consagração nos domingo e no clamor de meio dia, quase todo dia eu estou na igreja. Isso pra mim é motivo de muita alegria e é um prazer. (SENHOR FREDRICKSEN).

Os depoimentos de Tio Barnabé e Senhor Jaiminho chamam atenção pelo fato de, embora relatarem a participação em atividades sociais na igreja e na associação, relatam não frequentar a unidade de saúde porque, respectivamente, não se sente doente e não é convidado. É preocupante esse fato, porque compromete o trabalho de prevenção de doenças e promoção da saúde que pode ser desenvolvido pela equipe de saúde. Isso suscita a necessidade de elaboração de estratégias para convidar esses idosos para participar dessas atividades e, desse modo, contarem com mais um espaço que possa lhes ajudar a ter mais qualidade de vida, percebendo a UBS como um espaço para cuidar da saúde, e não apenas da doença.

Também há outro fator que chama atenção nas falas dos entrevistados acima: a presença da dimensão religiosa. Durante toda a entrevista foi perceptível que se mostravam muito religiosos, sempre falando de Deus e do convívio com a comunidade religiosa. Ferraz et al. (2012) ajuda a refletir sobre essa questão ao afirmar a existência de uma relação direta entre envelhecimento, qualidade de vida e terceira idade. Diante as dificuldades, as mudanças e estresses do quotidiano, a religião surge como um suporte que lhes ajuda a vencer a tendência ao isolamento social bem como superar os problemas do dia a dia.

\section{Convívio e relacionamento familiar e comunitário}

Consoante Ferraz et al (2012), os idosos tendem muito a associar a qualidade de vida com os seguintes aspectos: a prática de exercícios físicos, acesso ao lazer, a realização de atividades intelectuais e, particularmente, o convívio com a família, a comunidade, a sociedade.

Nesse sentido, para Luz e Amatuzzi (2008), normalmente se pesquisa a velhice tendo como referência apenas os fatores negativos e as perdas, quando, na realidade uma das nuances positivas, um 
dos ganhos dessa etapa da vida seria a habilidade para lidar com as relações interpessoais devido às experiências acumuladas ao longo da vida.

A esse respeito, duas entrevistadas relataram que tem um bom relacionamento familiar, porém há certas desavenças e atritos, o que, na opinião delas, é comum no convívio familiar. "Eu vivo direito com minhas filhas, meus filhos, meu marido, aqui acolá nós damos umas cacetadas. Risos”. (DONA CLOTILDE).

Para Dona Benta,

Eu tenho um bom relacionamento com meus familiares, a minha família graças a Deus até hoje é bom. Certo que toda família tem umas desavenças... Tem um pouquinho de problemas, mas isso não é coisa da gente se entristecer, que pra dizer que tem família perfeita isso é mentira... Não tem, não existe... Toda família tem seus problemazinhos, mas são problemas fáceis da gente resolver. Me orgulho da minha família humilde que eu tenho. Não tenho o que dizer, tenho um pouco de diferença com uma família ou duas, como eu trabalho na comunidade representando, isso é coisa que acontece. (DONA BENTA).

Os depoimentos anteriores demonstram que as participantes estabelecem uma relação direta entre qualidade de vida e bom relacionamento familiar, interpessoal. A fala a seguir de Tio Barnabé, por outro lado, chama atenção porque ele afirma que tem dificuldade nas relações interpessoais pelo fato de cuidar dos netos:

É boa, tenho meus desentendimentos com minha mulher, mas isso faz parte de um relacionamento. A gente cria uns netos e eles dão um pouco de trabalho. Você sabe como é menino pequeno... Na minha comunidade me relaciono bem com todo mundo. Minha comunidade é pequena. Todo mundo conhece todo mundo e cada um depende dos outros.

Essa declaração traz à tona uma realidade bastante perceptível nos dias atuais: os avôs cada vez mais, em decorrência das mudanças estruturais da sociedade, vêm desempenhando a tarefa de ajudar na educação ou até mesmo assumindo totalmente a criação dos netos. Situação que apresenta aspectos positivos e negativos. É bom porque possibilita ao idoso sentir-se valorizado, importante ao desempenhar essa função, transmitindo os seus valores e pensamentos a outros; por outro lado pode-se constituir numa empreitada que gerará grande carga de estresse e preocupação. Por isso, a necessidade de se pensar sobre essa questão.

Já o Senhor Fredricksen e Dona Neves ressaltam a importância do convívio comunitário. “A minha convivência com minha família é muito boa, com meus filhos. Na minha comunidade, graças a Deus, todo mundo gosta de mim. Eu no tenho mal querença com ninguém, graças a Deus nunca fiz mal a ninguém. Eu vivo muito bem a donde eu moro". (SENHOR FREDRICKSEN). 
comunidade muito boa, a qual a família é toda conhecida. Tudo é uma família só e tudo agente vive muito bem, apesar de que todos se conhecer e todo mundo se gosta. (DONA NEVES).

Garcia e Leonel (2007) ajudam a refletir sobre a questão dos relacionamentos na terceira idade ao afirmar que as relações interpessoais desempenham um papel extremamente benéfico na qualidade de vida dessas pessoas. Tanto os vínculos familiares, como aqueles relacionamentos já existentes, antigos bem como aquelas novas amizades construídas nos grupos comunitários. Surge daí, a necessidade de se planejar e fomentar espaços de convivência em grupo a fim de contribuir para o sentimento de felicidade na velhice.

\section{Considerações Finais}

A realização desta pesquisa possibilitou conhecer melhor a percepção do idoso sobre o que seja a qualidade de vida na terceira idade, bem como entender suas relações no convívio familiar e comunitário, especificamente a sua concepção a respeito da participação em grupos, relações interpessoais e também sobre a prática de atividades físicas.

Com a colaboração dos seis idosos participantes desta investigação, foi possível constatar que o envelhecimento transforma não só a aparência física, mas acarreta uma série de mudanças que alteram profundamente a realidade dos que o vivem. Nesse sentido, é muito comum aparecerem inúmeras doenças. A maioria, porém, resulta principalmente do estilo e das condições de vida construídas ao longo do tempo.

Logo, a velhice não se trata apenas de um evento biológico, mas de uma fase da vida formada por diversos fatores intercorrentes e inseparáveis, tais como: as condições socioeconômicas, os aspectos culturais, os hábitos de vida, a situação familiar, as políticas públicas voltadas para essa parcela da população, o acesso ao serviço em saúde, entre outros. Sendo assim, a qualidade de vida na terceira idade envolve múltiplas dimensões. Alguns participantes inclusive destacaram ter qualidade de vida, o que demonstra que o envelhecimento não implica necessariamente em más condições de vida.

Nesse contexto, a prática de atividades físicas, a interação com grupos na comunidade e os bons relacionamentos interpessoais mostram-se importantes estratégias para ajudar no sentimento de bem-estar na velhice.

É importante, então, que o profissional da Enfermagem reflita que a assistência voltada aos idosos envolve não só o aspecto biológico, mas também o psicossocial, o qual expressa seus sentimentos e emoções, influenciando, consequentemente, a sua qualidade de vida. Isso implica na produção de um atendimento em saúde que não se centre apenas na recuperação e no tratamento de 
doenças, mas também na prevenção e na promoção da saúde. Tanto que alguns idosos citaram a participação no grupo de idosos como importante para a sua interação social. Por outro lado, preocupa o fato de que alguns ainda não percebem a UBS como espaço de promoção da qualidade de vida, mas apenas para tratar da patologia.

Surge, assim, a necessidade de que outras pesquisas sejam realizadas a fim de se pensar mais estratégias para aproximar os idosos das instituições de saúde e, através dessa parceria, possibilitar uma vida mais saudável.

\section{Referências}

CELICH, K. L. S. Domínios de qualidade de vida e capacidade para a tomada de decisão em idosos participantes de grupos. Tese (Doutorado) - Pontifícia Universidade Católica do Rio Grande do Sul. Instituto de Geriatria e Gerontologia. Doutorado em Gerontologia Biomédica, Porto Alegre: PUCRS, 2008.

COSTA, H.O.; MATIAS, C.. O impacto da voz na qualidade da vida da mulher idosa. Revista Brasileira de Otorrinolaringologia, Brasília, v. 71, $\mathrm{n}^{\circ}$. 2, 2005, p. 172-8. Disponível em: <http://www.scielo.br/scielo.php?pid=S0034-72992005000200010\&script=sci_arttext $>$. Acesso em 05 mar. 2014.

CUNHA, L. L.; MAYRINK, W. C. Influência da dor crônica na qualidade de vida em idosos. Revista Dor, São Paulo, v. 12, nº. 02, 2011, p. 120-124. Disponível em: <http://files.bvs.br/upload/S/18060013/2011/v12n2/a2073.pdf >. Acesso em 02 mar. 2014.

DAWALIBI, N. W. et al. Envelhecimento e qualidade de vida: análise da produção científica da SciELO. Estudos de Psicologia, Campinas, v. 30, nº. 03, 2013, p. 393-403. Disponível em: <http:// www.scielo.br/pdf/estpsi/v30n3/v30n3a09.pdf >. Acesso em 06 mar. 2014.

FERRAZ, I. de L et al. Influência da orientação religiosa na qualidade de vida de idosos ativos. Revista Brasileira de Geriatria e Gerontologia, Rio de Janeiro, v. 15, $\mathrm{n}^{\circ}$. 03, 2012, p. 505-515. Disponível em: <http://www.scielo.br/pdf/rbgg/v15n3/v15n3a11.pdf〉. Acesso em 01 mar. 2014.

GARCIA, A.; LEONEL, S. B. Relacionamento interpessoal e terceira idade: a mudança percebida nos relacionamentos com a participação em programas sociais para a terceira idade. Pesquisas e Práticas Psicossociais, São João Del-Rei, v. 2, nº. 1, p. 130-139, 2007.

GIL, A. C. Como elaborar projetos de pesquisa. 4 ed., São Paulo: Atlas, 2012.

LEVIN, J. Estatística aplicada a ciências humanas. São Paulo: Harbra, 1985.

LINDEN JÚNIOR, E.; TRINDADE, J. L. de. Avaliação da qualidade de vida de idosos em um município do Sul do Brasil. Revista Brasileira de Geriatria e Gerontologia, Rio de Janeiro, v. 16, $\mathrm{n}^{\circ}$. 03, 2013, p. 473-479. Disponível em: 〈http://www.scielo.br /pdf/rbgg/v16n3/v16n3a06.pdf>. Acesso em 01 mar. 2014. 
MARCONI, M. de A.; LAKATOS, E. M.. Técnicas de pesquisa: planejamento e execução de pesquisas, amostragens e técnicas de pesquisas, elaboração análise e interpretação de dados. 3 ed., São Paulo: Atlas, 1996.

MINAYO, M. C. de S. O desafio do conhecimento: pesquisa qualitativa em saúde. São Paulo / Rio de Janeiro: Hucitec, Fiocruz, 2007.

NICOLUSSI, A. C. et al. Qualidade de vida em idosos que sofreram quedas: revisão integrativa da literatura. Ciência e Saúde Coletiva, Paraná, v. 17, no . 03, 2012, p. 723-730. Disponível em: <http://www.scielo.br/pdf/csc/v17n3/v17n3a19.pdf>. Acesso em 02 mar. 2014.

VAGETTI, G. C. et al. Domínios da qualidade de vida associados à percepção de saúde: um estudo com idosas de um programa de atividade física em bairros de baixa renda de Curitiba. Ciência e Saúde Coletiva, Paraná, v. 18, no 12, 2013, p. 3483-3493. Disponível em: <http:// www.scielo.br/pdf/csc/v18n12/a05v18n12.pdf>. Acesso em 05 mar. 2014.

\section{Como citar este artigo (Formato ABNT):}

BRAGA, I.B.; BRAGA, E.B.; OLIVEIRA, M.C.A.; GUEDES, J.D. A Percepção do Idoso sobre a Saúde e Qualidade de Vida na Terceira Idade. Id on Line Revista de Psicologia, Abril de 2015, vol.9, n.26, Supl. Esp. p. 211-222. ISSN 1981-1189.

Recebido: 08/02/2015

Aceito:13/02/2015 